\title{
Sustainable solutions for cost effective rainwater harvesting in Nepal: pilot project STORAGE realised in Kathmandu valley, Patan
}

\author{
Z. Boukalová ${ }^{1}$ \& J. Těšitel ${ }^{2}$ \\ ${ }^{1}$ VODNÍ ZDROJE a.s., Czech Republic \\ ${ }^{2}$ University of South Bohemia, Czech Republic
}

\begin{abstract}
According to official statistics more than a billion people in the world do not have access to a water supply. Groundwater resources face increasing pressure induced by particular land use practices and demand for drinking water. In some areas, groundwater levels have decreased, which has consequently negatively impacted on the quality of water. In the research work in Nepal, Kathmandu Patan area, we focus on new methods of rainwater harvesting which are aimed to increase groundwater recharge. It is done in localities meeting two criteria where the abstraction rate of groundwater exceeds that of natural infiltration, and where suitable hydrogeological conditions occur. The research strategy also included the socio-cultural aspect. In-depth understanding of local knowledge concerning historical practices of rainwater harvesting, as well as understanding the current community's needs appear to be of crucial importance when trying to implement any new technology. Therefore, mapping the situation on particular (pre-selected) localities became the first step of our research strategy

The paper reports on preliminary outputs achieved by the EUREKA project STORAGE, namely on our research, technological strategy and in-situ work, in particular pilot sites in Patan, Nepal.

Keywords: rainwater harvesting, monitoring, groundwater, integrated water resources management, pilot communities, Nepal.
\end{abstract}




\section{Introduction}

Intensive migration of the Nepalese population to Kathmandu valley began about 15 years ago. Currently the number of inhabitants in Kathmandu valley is estimated to be around four million and the population growth rate in the last decade is $61.23 \%$ [1]. Because of an increasing immigrant rate, the Kathmandu valley suffers from a severe drinking water supply crisis, particularly in the dry seasons of every year. To mitigate the crisis, nearly all sources are continually under exploitation, including groundwater from various aquifer, shallow; one of few meters to deep; one of several hundred meters. At the beginning of the last century, water was channelled to the centre of Kathmandu valley by an aqueduct from springs lying outside the city. Each inhabitant could take drinking water from some of the fountains. In addition to this official source of drinking water almost every bigger house in Kathmandu had its own well, which provided service water. There was minimal waste; organic waste was composted, and flushing toilets were unknown. Problems arose only when the Nepal capital started to approximate the West and from the civilization possibilities it chose some development options. The King had the aqueduct built in Kathmandu, but the sewage and sewage plants were only sparsely constructed. Water mains brought the comfort of water to households and its consumption rose, the rising volume of wastewater started to endanger the quality of groundwater [2]. Today, the water supply of Kathmandu is secured mainly (especially in the North of the city) by the Water Sources Company (Kathmandu Upatyaka Khanepani Limited) who pumps water from rivers and springs in the detrital areas of the outer Himalaya chain. This supply is not sufficient for the city (it covers about $50 \%$ of the demand), and the majority of inhabitants (mainly from peripheries of the capital and Patan) depend on individual pumping of groundwater [3]. For example, in the South of Kathmandu, in the centre of ancient Patan, local people depend on taking groundwater from wells or public fountains and gargoyles, because the water main there functions only 1-2 times per week for 2-3 hours [4]. The lack of groundwater here is solved by the system of infiltration wells; these wells serve the infiltration of precipitation water into underground collectors and in such way they are enhancing the sources of groundwater (shallow aquifer). By the way, they could raise not only the volume of available water artificially, but also its quality.

\section{Hydrogeological situation in Patan}

Shallow groundwater is the most important source of water for many residents in the core part of Patan. The area has benefitted from being located in the middle of the south to north gentle sloping terrace with gravel deposits. Rainwater falling on the surface infiltrates to recharge the groundwater. The trend of surface sealing and concretization due to increased urbanization, increasing water demand, disappearance of traditional recharge ponds have resulted in a depletion/lowering of the shallow groundwater level in the area. Most of the traditional water sources have dried out and artificial recharge appears to be the 
only solution available to revive these sources. Artificial recharge however tends to be case specific depending largely on local hydrogeology and rainfall. Past studies [5] have shown potential for rainwater recharge in Patan area. Differences in the water levels in the dry and wet season clearly indicate that the sources for groundwater of shallow aquifer in the area is only rainwater recharge. Local geology, geomorphologic factors and rainfall variation testify a strong influence in the groundwater recharge rates. Areas dominated by coarse sediments have a high to moderate infiltration rate.

\section{Possibilities of rainwater recharge sites in Patan}

Project E!6731STORAGE: tools and technologies for effective use and protection of groundwater selected Patan as the pilot area for rainwater harvesting technologies and related best practice training. The main goal of this project (in third world countries such as Nepal) is to select a typical pilot site(s), where the infiltration experiment will take place in order for the technology to meet the requirements of the local communities, respect legislation and legislative recommendations of the country and be effectively transferable to similar communities. For the project (which runs from 1 March 2012 till 31 December 2014), we have selected, on the basis of previous research and recommendations of the PÁNí project [2], seven typical sites in Patan, where it would be possible to perform the infiltration experiments. This selection was based on the fact that Patan inhabitants are forced to choose a strategy of a combination of several sources of water - water mains, purchase of "bottled water" and mainly return to original sources - wells, fountains and gargoyles. In the same time, the use of fountains, gargoyles and wells in Patan faces the following limits:

- More people means more consumption, which in turn leads to increased water abstraction from the aquifer without, however, sufficient saturation of this aquifer. This results in a gradual lowering of the groundwater level, which leads to the fact that some of the wells and fountains systems are drying (at least in periods of drought);

- Ponds designed to saturate the aquifer generally fell victim to the advancing urbanization - today a built-up area is there instead of ponds;

- The establishment of a central water supply system led to the destruction (or at least rudimentalization) of local knowledge (and institution) of management of a local water resource.

The Patan communities, that live there in the so-called "bahals" (i.e. in the area that defines each community and its joint action and decision-making; bahal always consists of several families - between 10 and approx. 25, rarely even more), are solving the situation of water supply individually (though from the same shallow aquifer). Since 2006, there has been a gradual use of wells (which 
may be even 100 years old; they are almost at all bahals and originally were used for religious purposes) as sources of drinking water and service water for the community. However, in the course of time, even these wells are not enough to supply the existing communities, due to advancing lowering of groundwater levels, and so it is necessary to take the next step - build infiltration facilities/reservoirs/wells where there is infiltration of rainwater (which originally drained away to sewers and the Bagmati River) into the upper groundwater aquifer.

After consultation with local experts and field reconnaissance, the set of sites was restricted to four typical locations, where field research was subsequently conducted and the following possible pilot localities for STORAGE project implementation were selected:

\subsection{Machhindra Bahal}

It is in fact a "square" with 26 households living there. They form a separate and clearly defined community. Currently, the households abstract water from two wells, one historical, one built in 2012 (within the Czech development assistance), from a depth of approx. $9 \mathrm{~m}$ below ground level. The square serves as an infiltration area - there are two infiltration wells which were built in 2008. Bahal residents tend to extend this system, because the current system of abstraction and infiltration of rainwater for 26 families living there is not sufficient.

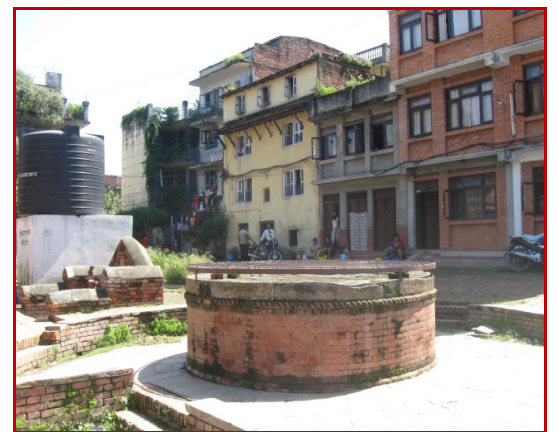

Figure 1: Historical well at Machhindra Bahal.

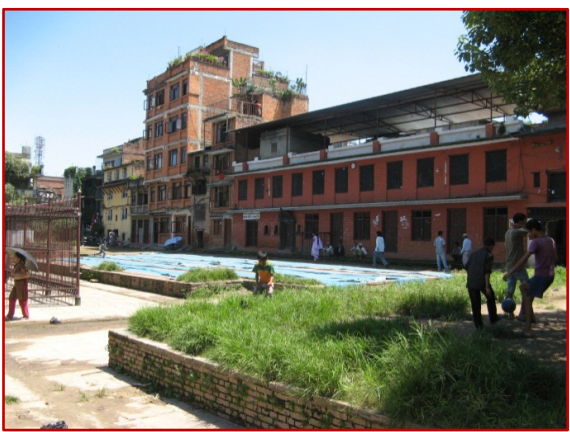

Figure 2: Machhindra Bahal overall view.

\subsection{Minnath Bahal}

The same type locality, a "square"-defined community with 20 households. Similar to the previous case, they abstract water from two wells; in the area of the square there is a simple but effective system of infiltration. The households aim to extend this system. For the time being, they solve the situation by themselves, with the assistance of UMES organization. 


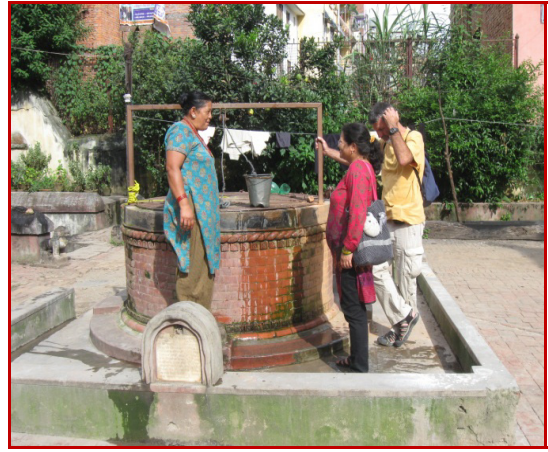

Figure 3: Minnath Bahal -
discussion on the topic
"what next"

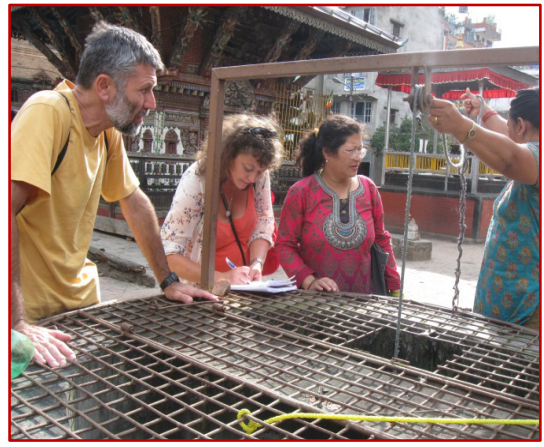

Figure 4:

\begin{abstract}
Minnath Bahal discussion on the topic "what next".
\end{abstract}

Both of the above mentioned communities are well organized, ready and willing to cooperate.

\subsection{Prayag Pokhari}

The site in question is the school premises, where in the past there was an infiltration pond (it is a hard surface today), which was used for religious purposes and also contributed to the saturation of one of the fountain's cascades in Patan. Under the project, it would be possible to restore its original function due to infiltration of rainwater (collected from the school roofs) into the upper aquifer in the area of interest. Ownership relations are not a problem in this case, on the contrary, representatives of the school have expressed interest in

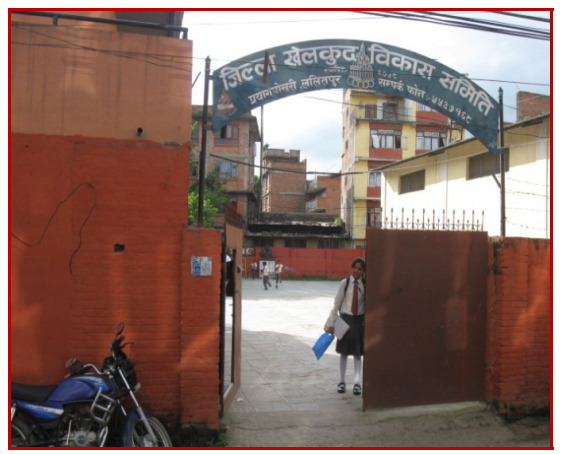

Figure 5: Entrance to the school premises.

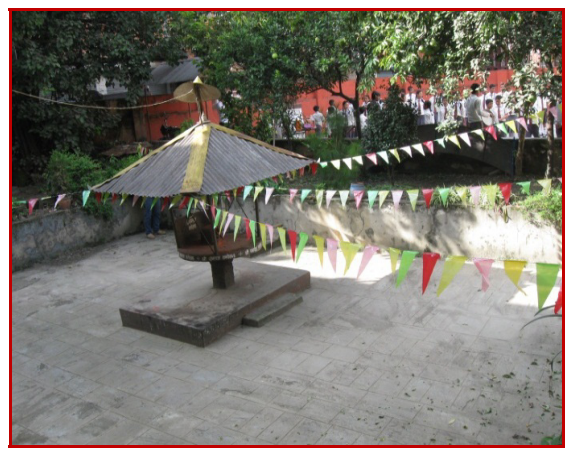

Figure 6: Hard surface - formerly infiltration pond. 
cooperation. At present, there is no source of water in the school area and the water must be supplied by the tanks. Thus the results of the project will be on two levels: a) the new accumulation well for the school will be drilled and b) as well the spouts in the surrounding area will be supplied by the rainwater recharging to the shallow aquifer. Moreover, work at the site might also have an educational character by involving local schoolchildren, who during their lessons could assist the project in the form of playing games.

\subsection{Kani Bahal (Nahity)}

Kani Bahal is a location, which is a "public space" and a place where water collects, which then saturates one of the cascade lines of public fountains. Water for infiltration would also be collected here from the roofs of surrounding schools and recharged into the infiltration borehole near the storage well (source of water for fountains). The agreement with the users/owners of the space in question would in principle be possible, but it is also necessary to resolve the source of water for schools, which will deliver water from the roofs.

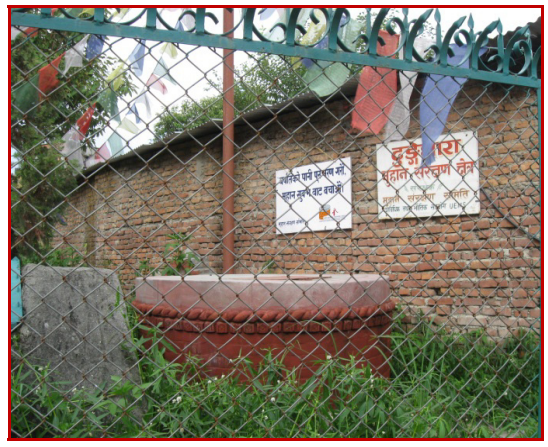

Figure 7: $\quad$ Source of water for Figure 8: fountains.

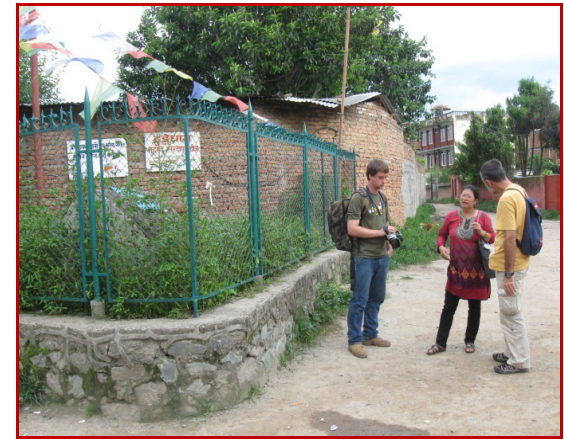

Source of water for fountains.

The above mentioned examples of optimum sites may serve for the formation of two institutional models of infiltration of rainwater that would be transferable to similar sites not only in Patan, but also in Kathmandu itself, etc. From the institutional point of view the two models differ by a degree of unambiguousness of the abstraction-saturation relationship.

Wells: from the urban point of view, the historical part of Patan consists of small or larger squares (bahal), with a temple and temple-related well located in their centres. Also the community living on the square and using its water resource is usually defined by the square. Should the infiltration system be implemented on the square in question, the abstraction-saturation relationship is quite clearly and simply defined both spatially (the square in question), and socially/institutionally (the community in question). 
Fountains and gargoyles: a fountain is not an isolated source. In Patan, there are several "lines of cascades", where the water from one fountain is transferred to the next one; the entire line is saturated from a single source. In this model, the abstraction-saturation relationship is much more open, spatially and thus also socially. Simply put, those who abstract water may not be aware of where and how the source they use is saturated. In these cases, it is possible within the site where water for fountains is collected to also meet the needs of those who deliver water for infiltration (e.g. from the roofs of schools) by building a local source.

The aforementioned two models represent two typical problem situations in the historical part of Patan. They should both be analysed and solutions should be found. Therefore, we recommend choosing two pilot sites for fieldwork in 2013:

Minnath Bahal: the community is ready to cooperate; there exists a functional institution that regulates water abstraction from the well; they have prepared a plan of how to use more water acquired; ownership relations are not a problem. In this respect, the situation does not differ from that at Machhindra Bahal. Giving priority to Minnath Bahal can be justified as follows:

- Research is inevitably linked with the practical construction of the appropriate infrastructure, i.e. it can be interpreted also as specific assistance to the community in question.

- This "assistance" should be "spread out" in order not to favour too much one community (where, for example, already in the past, international development assistance was provided).

- From this perspective, Minnat Bahal seems to be more appropriate than Machhindra Bahal, where they have already "become accustomed" to external assistance and within donations a storage well (VODNÍ ZDROJE, a.s., 2012) and 2 infiltration wells (UMES, 2008) were installed there.

Prayag Pokhari: in this area there existed in the past a reservoir designed for infiltration, the project would thus help to restore the original situation. As mentioned above, the area concerned is school premises. This situation could be used to promote the project and activities which it represents, to the "prospective" target group - the young generation.

\section{Conclusions}

Fieldwork in Patan (Kathmandu) will take place in the period August-September 2013 on the basis of discussions with local collaborators (UMES, CISD), the resulting number of selected pilot sites for the actual field survey will be given by the financial scope of the project. At the selected pilot site(s), an in situ project of rainwater recharge will take place within the following phases: 
- Development of new technology (testing of "best practices" and existing approaches to rainwater recharge, testing of the new technology of optimum rainwater recharge within the framework of selected pilot sites). The specific design of infiltration facility will be chosen in accordance with the local conditions in cooperation with communities.

- Analysis of end users for the needs of transfer of technology.

The principal objective of the research will be to study the rainwater recharge potential and its impact on the local groundwater system in Patan. Specific research objectives will be:

- Understand the efficacy of the recharging methods in recharging a shallow groundwater aquifer to enhance availability of water by verifying effectiveness of the various recharge methods identified by previous studies (by UEMS).

- Understand the recharge rate with different types of surfaces to augment shallow water aquifer by rainwater harvesting techniques.

- Study the effect of rainwater in shallow groundwater aquifer in the locality in terms of quality.

- Evaluate open spaces like bahals for rainwater recharging compared to the roof area.

Results of the STORAGE project will be not only the recharge of the aquifer and availability of water for the bahal/school area, but also an estimation of a preparedness of the pilot site (community) concerned to cooperate (institutional, socio-economic and possibly cultural preparedness), evaluation of the potential impact of the implementation of project activities (spatial, social, institutional and "educational") and estimation of repeatability of the proposed solution in the Patan, Lalitpur district and as well in other similar areas.

\section{Acknowledgements}

This paper was developed thanks to the E!6731 EUREKA project STORAGE (Sustainable TOols for gRoundwater manAGEment optimisation and water scarcity mitigation), financed by the Ministry of Education, Young and Sports, CR.

\section{References}

[1] Center Bureau of Statistics, Government of Nepal (2011): Major Highlights, Nepal.

[2] PANÍ (2008-2010): Solution of problems of groundwater quality and quantity in the region of Kathmandu (Nepal) on the basis of experience of Czech hydrogeologists in providing drinking water for Praha. (twinning project of international cooperation of the capitals of Praha and Kathmandu within the frame of establishing expert activities, promotion and transfer of 
knowledge and technology in the sphere of research of groundwater and its permanent utilization). VODNÍ ZDROJE, a.s., financed by City Prague, CR.

[3] GISIDC - Geographic Information System and Integrated Development Center, Ltd. (2011); Integrated Water Resources Management in Nepal pilot project Water for Kathmandu, Nepal.

[4] CISD - Center for Inclusive Social Development (2012): Water for Machindra Bahal community (Patan, Kathmandu, Nepal).

[5] UEMS (2012): Action Research on "Implication of Harvested Rainwater in Recharging Shallow Ground Water (GW) Aquifer and Its Quality”, Nepal. 